\title{
Being a Teacher of Holistic Profession: A Perspective of Transformative Learning
}

\author{
Xudong Zhu \\ Faculty of Education, Beijing Normal University, China \\ jianli2og@bnu.edu.cn \\ Jian Li \\ China Institute of Education and Social Development, Faculty of Education, \\ Beijing Normal University, China \\ jianli2og@bnu.edu.cn
}

\begin{abstract}
This study explores how to be a teacher of holistic profession from a perspective of transformative learning. Cultivating holistic profession in transformative learning involves the process of changes in communicative and instructional learning, the process of learning practical experience, and the process of critical reflection. These transformative learning processes contribute to the construction of teachers' holistic profession contextually. The rationales of applying a perspective of transformative learning concentrate on three major reasons. Cultivating teachers' profession as one type of adult learning is the core subject of transformative learning. Development serves as core idea of teachers' holistic professional consciousness. The learning transformation occurred from semi-profession to holistic profession. In this sense, the transformative learning model for teachers' profession is initially proposed to identify a special lens to shape an explicit pathway of being a teacher of holistic profession. In this model, transformative learning involves identifying "learning being professional". Transformative relationship focuses on "teaching being professional". Transformative context view concentrates on contenting being professional. Transformative context view involves contenting being professional. The conclusion and remarks are offered to summarize the rewards of being a teacher of holistic profession.
\end{abstract}




\section{Keywords}

holistic professional consciousness - teacher education - transformative learning theory - basic education - teachers' profession - teacher education

Teacher plays an inevitably significant role in the field of basic education worldwide. In recent decades, teachers' professional development as one of the most important concepts in the field of teacher education involves the construction of dynamics and self-selective development (Brown, 2009; Carter, 2002; Christopher et al., 2001; Clark and Wilson, 1991). It is also identified as the state of all-round development academically, practically and politically (Clark and Wilson, 1991). Promoting teachers' professional development focuses on constructing the foundations and mechanisms related to how to boost teachers' all-round development and what strategies should be used eventually. In addition, the nature of teacher profession is summarized into three dimensions, including teaching students how to learn, educating people, and serving for all (Zhu, 2014, pp. 82-83). All those three dimensions of teachers' profession offer a relatively comprehensive landscape to explore how to cultivate teacher's professional capacities. Specifically, the dimension of teaching students how to learn includes three layers: the first layer focuses on cultivating students to learn how to study through reading, observation, discussion and other skills. In this process, the learning capacity is gradually enhanced through the actively engagement of curiosity, autonomy, initiative, persistence, and reflection; The second layer supports students to learn to recognize cognitive knowledge, including primary and advanced cognition, such as remembering, perceiving, analyzing, judging, reasoning, decision-making, thinking styles, language construction, concept formation, knowledge representation, problem solving, creativity, and metacognition; The third layer focuses on encouraging students to learn disciplines of basic education curriculum; The fourth layer involves supporting students to think critically, acquire information, solving problems, reflecting and improving themselves, creating new ideas, products and solutions; The fifth level engages students to learn how to live in a diverse learning community independently, cooperatively and inquiringly. In other words, from a practical viewpoint, teaching is guided by a series of training of qualified teachers. In particular, dimension of educating people is associated with cultivating "all-round developed" person with the integrity of cognitive and emotional features. Educating people tends to the cultivation of individuality, 
sociality and personality in regard to the physical education, mental education, social education, and spiritual education. Dimension of serving for all includes offering various professional service educational organizations at both administrative and professional levels.

In addition to the three major dimensions of teachers' profession, the concept of holistic profession is initiated to cultivate teachers' learning and teaching profession, focusing on teaching students to learn, cultivating students and serving (Zhu, 2014, p. 82). In addition, teachers' holistic profession involves couples of questions, such as how to apply the idea of holistic profession to teach? What core ideas related to gaining the skills of holistic professional consciousness? And what specific tacit teachers should obtain? All these questions contribute to identifying three major attributes of teachers' holistic professional consciousness, including teaching being professional, learning being professional and contenting being professional. In the domain of teachers' holistic profession, the ultimate goal is to the construction of allround student-centered development, which mainly including cognitive learning, emotional learning, moral and citizenship learning, personal and sociality learning, health and security learning, artistic and aesthetic learning (Zhu, 2017, p. 54). The pedagogical idea of teachers' holistic profession is fundamentally epitomized to three key components: learning being professional, teaching being professional, and contenting being professional (Zhu, 2017, p. 54).

However, constructing a learning pathway concerning on being a teacher of holistic profession is considered a pivotal point to narrow an existed gap between the conception and practice. Thus, this study aims to pedagogically explore how to be a teacher of holistic profession through a perspective of transformative learning theories. Specifically, firstly, processing teachers' holistic profession involves the process of explicit changes in communicative and instructional learning, the process of learning practical experience, and the process of critical reflection. All these transformative learning process contributes to shaping teachers' holistic profession contextually; Secondly, rationales of applying a perspective of transformative learning are comprehensively discussed to offer solid foundation on applying a perspective of transformative learning. Cultivating teachers' profession as one type of adult learning is the significant subject of transformative learning. Development serves as core idea of teachers' holistic profession. The learning transformation occurred from semi-profession to holistic profession. Thirdly, the transformative learning model is to shape an explicit pathway of being a teacher of holistic profession. Transformative learning, transformative relationship and transformative context serve as three core dimensions to construct holistic profession. Transformative learning involves identifying "learning being professional". Transformative relationship focuses on "teaching being professional". Transformative 
context view concentrates on contenting being professional. A Transformative context view involves contenting being professional. Lastly, the conclusion and remarks are epitomized to the development of being teachers' holistic profession.

\section{Cultivating Holistic Profession in Transformative Learning}

Being a teacher of holistic profession is essentially developed in the process of transformative learning. In particular, teachers' holistic profession is fundamentally constructed in the process of changes in communicative and instructional learning, the process of learning practical experience, and the process of critical reflection. All these transformative learning process all contributes to shaping teachers' holistic profession contextually.

Specifically, teachers' holistic profession is created in a process of learning changes, which engaging in transformative learning. The concept of transformative learning (Mezirow, 1991, 1995, 1996; Cranton, 1994, 1996) involves a process of inevitable learning changes in a frame of reference, which shaping a coherent subject of learning experience, including associations, concepts, values, feelings, conditioned responses (Boyd, 1991; Brookfield, 1986; Clark, 1993; Carter, 2002). It focuses on shaping learning expectations, perceptions, cognition, and feelings of individual. In other words, transformative learning focuses on mental or behavioral learning process, which including inclusive, discriminating, self-reflective, and integrative of experience (Christopher et al., 2001; Cohen, 2004; Daloz et al., Eisen, 2001). In the field of education, the transformative learning is reconstructed through faming the both objective and subjective learning actives.

Regarding to building holistic professional capacities, in particular, being teachers' holistic profession is fundamentally rooted in the communicative and instructional learning. Through facilitating transformative learning, educators have a tendency to support learners to be aware of their own learning assumptions (Feinstein, 2004; Taylor, 2017; Gu et al., 2010). In other words, learning involves a social process, and discourse becomes central to making meaning. Effective learning discourse concentrates on how to support teachers to create equal opportunity to make a tentative best judgment to influence actions of teaching and learning. In addition, Mezirow (1996) argued that, "learning is understood as the process of using a prior interpretation to construe a new or revised interpretation of the meaning of one's experience in order to guide future action." (p. 162). It is often applied in the area of adult education to investigate how to support individual to be a transformative learner of self-reflective and self-management. 
In addition, teachers' holistic profession is constructed in a process of learning practical experience. A couple of studies focus on examining the logic of Mezirow's conception of transformative experience through identifying the autonomy and applicability of teaching and learning practical experience (Tran, 2012; Ritz, 2010, Lyon, 2001; McDowell, 2012). Identifying transformative experience involves various stages of learning transformation, which shaping teachers' practices particularly (Taylor 1998). Hence, offering a more holistic interpretation of transformative learning is associated with exploring action, relationships, context, critical reflection, and power. The transformative learning theory mainly focuses on examining the role of critical learning reflection in the learning process.

Moreover, teachers' holistic profession is also established in a process of critical reflection of transformative learning. The critical reflection is considered as one key stage of constructing transformative learning as well as fully discussed by Merriam (2004). Critical reflection as the cognitive development involves a series of mindsets, focusing on shaping self-directed manners for individuals (Mezirow, 1991; 1995; 1996; 2000). Lots of studies concentrate on identifying different elements that contributing to individual's critical reflection and personal development in order to better understand how critical reflective competencies received by individuals (Scott, 1992; 1997). In addition, the critical reflection is also associated with the practice of fostering transformative learning specifically.

To sum up, cultivating teachers' holistic profession mainly involves the transformative learning, including the process of changes in communicative and instructional learning, the process of learning practical experience, and the process of critical reflection. In this sense, the pedagogical learning approaches aim to provide students sufficient educational support to guide their specific practice and explain the inevitable learning changes. Regardless of different contextual situation, the formal settings of universities and colleges offer particularly informal and formal teaching to provide external influences in the process of transformative learning. Essentially, in the transformative learning process, fostering critical reflection is parallel to accelerating the transformative learning in terms of implementing a series of instructional strategies. Cultivating critical reflection involves the improvement of the awareness of students' perceptions and personalities in the process of transformative learning. In order to foster transformative learning, identifying the roles of students and teachers is pivotal in the classroom. It is also related to couples of questions, concerning on how to understand the relations between teachers and students and how to engage students actively participating in transformative learning. Within the classroom of applying transformative learning, the relations between students and teachers are identified to promote learner's 
learning outcomes. Along with processing holistic profession in transformative learning, rationales of applying a perspective of transformative learning are separately identified in next part.

\section{Rationales of Applying a Perspective of Transformative Learning}

The rationales of applying a perspective of transformative learning to examine a pathway of being teachers of holistic profession mainly concentrate on three major reasons. Specifically, cultivating teachers' profession as one type of adult learning is the core subject of transformative learning. Development serves as core idea of teachers' holistic profession. The learning transformation occurred from semi-profession to holistic profession.

\subsection{Cultivate Teacher's Profession as Adult Transformative Learning}

Cultivating teachers' profession as one type of adult learning is the core subject of transformative learning. In particular, in the field of transformative learning, the training of adult learning serves as key point of the construction of transformative teaching and learning. In other words, training teachers' holistic profession is inherently obsessed with advocating and respecting adult learning principles. There existed obvious consistency between cultivating teachers' profession and advancing adult learning process. Along with the core nature of adult transformative learning, teachers' holistic profession is embodied in shaping disciplinary logic and humanism-oriented development. Cultivating teachers' holistic professional consciousness is parallel to training adult learning practices in transformative learning (Mezirow, 1991; 1995; 1996; 2000).

\subsection{Development as Core Idea of Teachers' Holistic Profession}

The development is considered as core of teachers' holistic profession. Specifically, holistic profession for teachers is understood as growth, which is similar to Mezirow (1991)'s transformative learning. It motivates teachers to engage in formal learning experience and process. The growth of learning and teaching for promoting teachers' profession occurred in the specific developmental movement. For example, when teachers participated in formal learning experiences, they devoted themselves in the development of learning and teaching experiences. In addition, the growth and transformation of learning and teaching are grounded in the educational developmental movement within the sociocultural context of educational experience. Essentially, Daloz' theory of transformative learning involves the constructivist concept of teaching and learning, which depending less on rational, reflective acts and relying more on the holistic professional development. Thus, according to Daloz's perspective, 
transformative learning aims to promote the developmental construction of learning and teaching, which illustrating the psychological, social and developmental context. In a transformative pedagogy, formal educational developmental experience plays a critical role in helping teachers recognize the process of learning construction (Daloz, 1986; Daloz et al., 1996; Deems, 1996; Dirkx, 1995; 1997).

4

\section{Transformative Learning from Semi-profession to} Holistic Profession

The learning transformation occurred from semi-profession to holistic profession. In the model of teachers' holistic professional consciousness, the incremental transition from semi-profession to holistic profession demonstrates the nature of transformative learning actually (Zhu, 2017a; 2018). Specifically, the idea of semi-profession is recognized to neglect student-centered educational development. Thus, it is not easy for teachers to shape the coherences between curriculum and student-centered teaching (Taylor, 1994; 2017; Taylor \& Cranton, 2012). Moreover, the negligence of students' comprehensive physical and mental development is also criticized in terms of the ignorance of students' psychological and physically variation in the specific learning process. In this sense, in order to mitigate the shortcomings of semi-profession in current Chinese basic education, the idea of holistic profession is proposed to advocate such core features of learning being professional, teaching being professional, and contenting being professional. Hence, the learning transformation in regard to teachers' profession explicitly involves the changes from the state of semi-profession, neglecting individual's mental and physical development to the holistic profession, focusing on integrating learning being professional, teaching being professional and contenting being professional.

\subsection{A Transformative Learning Model Related to Being a Teacher of Holistic Profession}

The transformative learning model related to the teachers' profession is proposed to identify a special lens to shape an explicit pathway of being a teacher of holistic profession. Through reviewing the literature, transformative learning, transformative relationship and transformative context serve as three core dimensions to construct holistic professional consciousness. Specifically, within this model, transformative learning involves identifying "learning being professional". Transformative relationship focuses on "teaching being professional". Transformative context view concentrates on contenting being professional. A Transformative context view involves contenting being professional. 


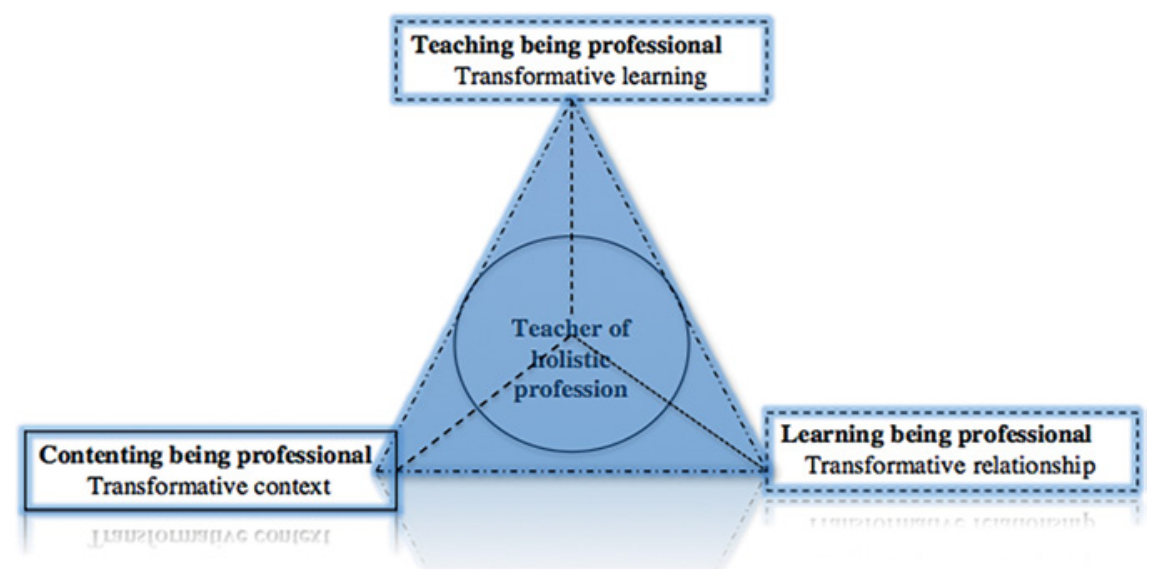

FIGURE 1 A transformative learning model related to being a teacher of holistic professionResources: Retrieved from Zhu, X. (2017a). On the Attributes of the Teacher's "Holistic Profession”. In Quality of Teacher Education and Learning (pp. 53-67). Springer, Singapore.

\subsection{A Transformative Learning View on "Learning being professional"}

In the domain of transformative learning theory related to training teachers' process, the transformative learning is inherently associated with identifying the presence of reflection in learning being professional. Transformative learning shed more light on the nature of learning being professional. As one key components of the proposed idea of teachers' holistic profession, learning being professional is correlated to the practical efforts as the foundation of specific educational changes, encompassing teachers' learning of students, designing for students' learning and of evaluating students' learning.

In particular, there existed a series of studies on exploring teachers' learning process through a perspective of transformative learning (Taylor 1998; Liimatainen et al. 2001, Cranton and Carusetta 2004, Kreber 2004). For example, Cranton and Carusetta (2004) conducted a longitudinal research on examining the authenticity in teachers' training process for the ongoing critical reflection. Kreber (2004) investigated teachers' self-regulated learning, applying models of transformative learning perspectives. He used Mezirow's transformative learning model to build three dimensions of instructional knowledge, pedagogical knowledge, and curricular courses. The transformative learning aims to stimulate teachers' critical reflection to integrate both teaching knowledge and teaching experience. Thus, both pedagogical and instructional transformative learning play a key role in fostering teachers' professional reflection. In addition, Kreber (2004) also argued that, in the process of transformative learning, the 
group of teachers is expected to enhance critical and reflective learning relatively. The development of clear indicators of constructing transformative learning is essential to illustrate how to verbally articulate the significance of transformative learning during their teaching practice particularly. In response to this, Liimatainen et al. (2001) also constructed semi-structural interviews to examine how to support teachers remembering reflective moments and providing a medium to stimulate their critical reflection throughout the transformative learning process. Liimatainen et al. (2001) also suggested that the developmental nature of transformative learning for training teachers' learning is to cultivate their mature cognitive learning development as a foundational attribute in critical reflection and rational discourse (Zhu, 2017a, p. 6o).

\subsection{A Transformative Relationship View on Teaching Being Professional}

Teacher-student relationship is considered as a core of teaching being professional in the concept of teachers' holistic professional concepts. Specifically, teachers' holistic profession contains couples of features of teaching being professional, such as teachers' self-identity construction, teaching design, teaching implementation and teaching evaluation (Zhu, 2017, p. 61). All these elements of shaping teaching being professional concentrate on exploring transformative relationship between teacher and students inherently.

Lots of studies have pointed out that the transformative relationship between teacher and students in the process of transformative learning. Specifically, establishing relationships between teacher and student is of the essential factors in a transformative experience (Taylor 1998). The transformative relations between student and teacher is regarded as a trustful relationship to allow them have questioning discussions, share information openly and achieve mutual and consensual understanding separately. Carter (2002) focused on offering insights into the complex nature of transformative relationships between students and teachers. Eisen (2001) created new insights on the nature of transformative dialogue and relationships (Lyons, 2001; Carter, 2002). In addition, regarding to the nature of transformative learning, couples of relationships related to acquiring skills and knowledge, enhancing self-image and friendship and imaginative relationships provide significant role to create intimate relationships between teachers and students. In addition to building intimate relations, the peer-learning relations also contribute to the professional development of transformative learning in various learning communities. In other words, the immerging relations among different peer groups, such as student and student, student and teacher, teacher and teacher, provide peer dynamic platform to enrich the process of transformative learning. The transformative learning is one of the most elusive learning models, focusing on 
a perspective transformation (Taylor 1998). Thus, the transformative relationship on teaching being professional is regarded as inherent characteristics of learners dealing with scheme change and epistemological change (Mezirow, 2000). The teachers' holistic profession is fairly consistent with emphasizing a psychological view of change in terms of different relations between teachers and students. In other words, the conception of a transformative relationship is gradually constructed to shape individual's transformative experiences.

\subsection{A Transformative Context View on Contenting Being Professional}

In the field of transformative learning theory, the transformative context is closely associated with contenting being profession for the cultivation of holistic profession. Contenting being professional means the reshaping of the content that supporting students to learn something. It involves certain subjects of various disciplines or majors in colleges and universities. For example, being a teacher is committed to examining how to reconstruct the specific contents of curriculum, including textbooks and syllabus. In other words, the reconstruction of certain content is rooted in cultivating teachers' holistic professions in order to shaping the understanding of the principle of students' learning and development. Contenting being professional serves one of integral features to cultivate a teacher with holistic professional consciousness. In regard to this illustration of contenting being professional, transformative context offer an additional lens to examining the nature of contenting being professional specifically. In other words, in reality, contenting being professional is occurred in specific contextual environment or situation with various requirements and principles.

Prior researchers did solid studies on investigating the significance of applying transformative context to cultivate qualified teachers. The transformative context plays a pivotal role in shaping transformative learning in the conception of transformative learning theory (Clark and Wilson 1991, Taylor 1998). For example, both personal prior life experiences and sociocultural contextual factors serve as significant indictors to delineate the key components of transformative context. In the meanwhile, a number of studies are subjective to clarity the nature of transformative context, which is different from the nature of perspective transformation (Courtenay et al. 2000, Baumgartner, 2002; King, 2000, Lyon, 2001; Jarvis 1999). In addition, the mechanism of teachers' self-controlling is constructed in transformative context (Kilgore and Bloom, 2002). In order to survive in the contexts of schools, teachers are required to make different kinds of changes to recognize the challenges as a transformational pedagogy. 


\subsection{Conclusion}

This study focuses on investigating being a teacher of holistic professional consciousness through a transformative learning perspective. The idea of being teachers of holistic profession refers to the cultivation of individual's teaching profession (Zhu, 2014, p. 82). Being teachers of holistic profession addressed a series of questions, including the examination of the idea of holistic profession, the skills of holistic profession, specific tacit of holistic profession. In addition, the attributes of teachers' holistic profession are examined that teaching being professional, learning being professional and contenting being professional. In the field of teachers' holistic profession, the cognitive learning, emotional learning, moral and citizenship learning, personal and sociality learning, health and security learning, artistic and aesthetic learning contribute to shaping the idea of holistic profession (Zhu, 2017a, p. 54). The holistic profession is associated in the process of explicit changes of communicative and instructional learning, learning practical experience, and the critical reflection, which shaping individual' holistic profession systematically. In addition, the rationales of the application of transformative learning explore the practical approaches of teachers' holistic profession in the regime of transformative learning. Advocating teachers' profession as one type of adult learning is the core subject of transformative learning. Development serves as core idea of teachers' holistic professional consciousness. The learning transformation occurred from semi-profession to holistic profession.

Moreover, a transformative learning model related to being a teacher of holistic profession highlights the vivid structure of teacher education. The transformative learning model is to offer a special snapshot to create practical pathway of being a teacher of holistic profession. Particularly, transformative learning, transformative relationship and transformative context concentrate on the construction of holistic professional consciousness. Specifically, transformative learning involves identifying "learning being professional". Transformative relationship focuses on "teaching being professional". Transformative context view concentrates on contenting being professional. A Transformative context view involves contenting being professional.

\subsection{Remarks}

Along with illustrating transformative learning theory, to be realistic, the corresponding foundation of teachers' holistic profession derived from the nature of teachers' ethical spiritual inspiration of knowledge and ability. Generally 
speaking, teachers' ethical spiritual inspiration refers to a couple of mindsets, including consciousness, thinking activity, professional awareness, and professional thinking activities. Comparatively speaking, teachers' ethical spiritual inspiration in Chinese context also denoted as one kind of national and contemporary spirit and patriotism. Moreover, the idea of professionalism of teachers is based on general internal spiritual forces, ethical identity, and traditional virtues. Engaging in cultivating the holistic profession of teachers is also related to the recognition of professional identity. In other words, only gaining the ethical spiritual inspiration, teachers would be shaped and cultivated to be holistic professional instructors with both professional identity and professional care.

In addition to promoting teachers' ethical spiritual inspiration, equipping with holistic profession for teachers also focuses on providing solid knowledge base on the teacher's profession. Additionally, the richness of teachers' knowledge is closely associated with the advancement of teachers' specialty. For example, if teachers hold a solid and broad knowledge base, they have more likely to do a good job in specific teaching profession, concentrating on general knowledge, subject knowledge, professional knowledge and practice for teachers. Professional knowledge is divided into theoretical knowledge and practical knowledge in the domain of pedagogy. Moreover, the cultivation of teachers' holistic profession also includes teachers' professional competence to solve various disciplinary problems.

In addition, teachers' holistic profession is incrementally realized through a certain mechanism in terms of applying various learning experience, reflection, evidence, data, concepts and theories. The mechanism of teachers' holistic professional development is expected to present accumulation of experience with characteristics of emotion and adaptation. Moreover, the professional statistical evidence-based data mechanisms are beneficial to create mechanism of teachers' holistic profession. It involves understanding the digital rationality and theoretical rationality to enable teachers constructing professionally, focusing on cognitive psychology, learning science, and moral development. In addition to building professional statistical evidence-based data mechanisms, both professional concepts and ideological mechanisms concentrate on grasping and forming professional concepts to achieve professional behavior as explicit intentions. Acquisition of professional concepts is associated with explaining and teaching students how to learn. Through constructing the connotation of teachers' holistic profession, transformative learning theories are used to investigate how to cultivate a teacher of holistic profession inherently. It is of significance for teachers to cultivate professional teaching and learning development. 


\section{Reference}

Boyd, R.D. (1991). Personal transformation in small groups: a Jungian perspective. London: Routledge.

Boyd, R.D., \& Myers, G.J. (1988). Transformative education. International Journal of Lifelong Education, 7(4), 261-284.

Brookfield, S.D. (1986). Understanding and facilitating adult learning. San Francisco: Jossey-Bass.

Brown, L. (2009). The transformative power of the international sojourn: An ethnographic study of the international student experience. Annals of tourism research, $36(3), 5^{02}-5^{21}$.

Clark, M.C. (1993). Transformational learning, In S.B. Merriam (Ed.), An update on adult learning theory (pp. 47-56). San Francisco: Jossey-Bass. (New Directions for Adult and Continuing Education, No.57).

Collins, M. (1991). Adult education as vocation: A critical role for the adult educator. London: Routledge.

Cranton, P. (1994). Understanding and promoting transformative learning: A guide for educators of adults. San Francisco: Jossey-Bass.

Carter, T.J. (2002). The Importance of Talk to Midcareer Women's Development: A Collaborative Inquiry. The Journal of Business Communication, 39, 55-91.

Christopher, S., Dunnagan, T., Duncan, S.F. and Paul, L. (2001). Education for Self-support: Evaluating Outcomes Using Transformative Learning Theory. Family Relations, 50, 134-142.

Clark, M.C. and Wilson, A. (1991). Context and Rationality in Mezriow's Theory of Transformational Learning. Adult Education Quarterly, 41, 75-91.

Cohen, J.B. (2004). Late for School: Stories of Transformation in Adult Education Program. Journal of Transformative Education, 2, 242-252.

Collard, S. and Law, M. (1989). The Limits of Perspective Transformation: A Critique of Mezriow's Theory. Adult Education Quarterly, 39, 99-107.

Courtenay, B., Merriam, S.B. and Reeves, P.M. (1998). The Centrality of Meaning-making in Transformational Learning: How HIV-positive Adults Make Sense of their Lives. Adult Education Quarterly, 48, 65-84.

Courtenay, B.C., Merriam, S., Reeves, P. and baumgarnter, L. (2000). Perspective Transformation over Time: A 2-year follow-up Study of HIV-positive Adults. Adult Education Quarterly, 50, 102-119.

Cragg, C.E., Plotnikoff, R.C., Hugo, K. and Casey, A. (2001). Perspective Transformation in RN-to-BSN Distance Education. Journal of Nursing Education, 40, 317-322.

Cranton, P. (1992). Working with Adult Learners (Toronto, ON: Wall and Emerson).

Cranton, P. (1994). Understanding and promoting transformative learning (San Francisco, CA: Jossey-Bass). 
Cranton, P. (2000). Individual Differences and Transformative Learning. In J. Mezirow and Associates (eds.) Learning as Transformation (San Francisco, CA: Jossey-Bass), pp. 181-204.

Cranton, P. and Carusetta, E. (2004). Perspectives on Authenticity in Teaching. Adult Education Quarterly, 55, 5-22.

Daloz, L. (1986). Effective teaching and mentoring: Realizing the transformational power of adult learning experiences. San Francisco: Jossey-Bass.

Daloz, L.A., Keen, C.H., Keen., J.P., \& Parks, S.D. (1996). Common fire: Lives of commitment in a complex world. Boston: Beacon Press.

Deems, T.A. (1996). Transformation and the spectrum of consciousness: A multidimensional perspective for the individual and group. In. J.M. Dirkx (Ed.), Proceedings of the fifteenth annual Midwest Research-to-Practice Conference in Adult, Continuing, and Community Education (pp. 46-51). Lincoln, NE: University of Nebraska.

Dirkx, J.M. (1995). Educating for vocational integration: The role of spirit and soul in education-for-work. In R. Orem \& C. Mealman (Eds.), Proceedings of the fourteenth annual Midwest Research-to-Practice Conference in Adult, Continuing, and Community Education (pp. 62-67). Dekalb, IL: Northern Illinois University.

Dirkx, J.M. (1997). Nurturing soul in adult learning. In P. Cranton (Ed.), Transformative learning in action. San Francisco: Jossey-Bass.

Eisen, M.J. (2001). Peer-based Professional Development Viewed through the Lens of Transformative Learning. Holistic Nursing Practice, 16, 30-42.

Feinstein, B.C. (2004). Learning and Transformation in the Context of Hawaiian Traditional Ecological Knowledge. Adult Education Quarterly, 54, 105-120.

Franz, N. (2003). Transformative Learning in Extension Staff Partnerships: Facilitating Personal, Joint and Organizational Change. Journal of Extension, 41, 1-9.

Freide, P. (1984). Pedagogy of the Oppressed. (New York: Continuum).

$\mathrm{Gu}$, Q., Schweisfurth, M., \& Day, C. (2010). Learning and growing in a 'foreign' context: Intercultural experiences of international students. Compare, 40(1), 7-23.

Hunter, A. (2008). Transformative learning in international education. Developing intercultural competence and transformation: Theory, research, and application in international education, 92-107.

Lange, E. (2004). Transformative and Restorative Learning: A Vita Dialectic for Sustainable Societies. Adult Education Quarterly, 54, 121-139.

Liimatainen, L., Poskiparta, M., Karhila, P. and Sjögren, A. (2001). The Development of Reflective Learning in the Context of Health Counseling and Health Promotion during Nurse Education. Journal of advanced nursing, 34, 648-658.

Lyon, C.R. (2001). Hear our Stories: Relationships and Transformations of Women Educators who Worked Overseas. Studies in the Education of Adults, 33, 118-26. 
McDowell, T., Goessling, K., \& Melendez, T. (2012). Transformative learning through international immersion: Building multicultural competence in family therapy and counseling. Journal of Marital and Family Therapy, 38(2), 365-379.

Merriam, S.B., \& Clark, M.C. (1991). Lifelines: Patterns of work, love, and learning in adulthood. San Francisco: Jossey-Bass.

Mezirow, J. (1991). Transformative Dimensions of Adult Learning (San Francisco, CA: Jossey-Bass).

Mezirow, J. (1996). Contemporary Paradigms of Learning. Adult Education Quarterly, $46,15^{8-172 .}$

Mezirow, J. (2000). Learning to Think like an Adult. In J. Mezirow and Associates (eds.) Learning as Transformation (San Francisco, CA: Jossey-Bass), pp. 3-33.

Mezirow, J. (1991). Transformative dimensions of adult learning. San Francisco: Jossey-Bass.

Mezirow, J. (1995). Transformation theory in adult education. In M.R. Welton (Ed.), In defense of the lifeworld: Critical perspectives on adult learning (pp. 39-70). Albany, NY: SUNY.

Mezirow, J., \& Associates. (1990). Fostering critical reflection in adulthood: A guide to transformational and emancipatory practice. San Francisco: Jossey-Bass.

Taylor, E.W. (1994). Intercultural competency: A transformative learning process. Adult education quarterly, 44(3), 154-174.

Taylor, E.W. (2017). Transformative learning theory. In Transformative Learning Meets Bildung (pp. 17-29). Sense Publishers, Rotterdam.

Taylor, E.W., \& Cranton, P. (2012). The handbook of transformative learning: Theory, research, and practice. John Wiley \& Sons.

Tran, L. (2012). Transformative learning and international students negotiating higher education. International students negotiating higher education: Critical perspectives, 124-141.

Ritz, A.A. (2010, March). International students and transformative learning in a multicultural formal educational context. In The educational forum (Vol. 74, No. 2, pp. 158-166). Taylor \& Francis Group.

Scott, S.M. (1992). Personal change through social action: A case study of ten social activists. The Canadian Journal for the Study of Adult Education, 6(2), 47-64.

Scott, S.M. (1997). The grieving soul in the process of transformation. In P. Cranton, (Ed.), Transformative learning in action (p. 4150). San Francisco: Jossey-Bass.

Sung, M., Yang, S. (2009). Student-university Relationships and Reputation:A Study of the Links Between Key Factors FosteringStudents' Supportive Behavioral Intentions Towards Their University[J]. Higher Education, 2009, (7).

Zhu, X. (2017a). On the Attributes of the Teacher's "Holistic Profession". In Quality of Teacher Education and Learning (pp. 53-67). Springer, Singapore. 
Zhu, X. (2017b). On the Whole Professional Attribute of Teacher Development [J].Journal of Huzhou Normal University, 39 (06): 1-3.

Zhu, X. (2014). On the Theoretical Model Construction of Teachers' Professional Development [J]. Educational Research, 35 (o6): 81-90.

Zhu, X., Li, Y. (2018). On the Connotation of Teachers' Professional Consciousness and Its Materialist Foundation [J].Journal of Yunnan Normal University (Philosophy and Social Sciences Edition), 50 (01): 116-123. 